\title{
Nitrite and nitrate levels in ileostomy effluent: effect of dietary change
}

\author{
BY B. C. RADCLIFFE ${ }^{1}$, C. HALL ${ }^{2}$ AND W. E. W. ROEDIGER ${ }^{3 *}$ \\ ${ }^{1}$ Cell Physiology Laboratory, ${ }^{2}$ Stomal Therapist and ${ }^{3}$ Department of Surgery, The \\ University of Adelaide at The Queen Elizabeth Hospital, Adelaide, S.A. 5011, Australia
}

(Received 8 February 1988 - Accepted 31 October 1988)

\begin{abstract}
1. Nitrite and nitrate levels were measured in samples from ileostomy bags or stomal samples of thirty-one ileostomists (twenty-two ulcerative colitis, nine Crohn's disease), 14-16 h after ingestion of a conventional meal or a meal containing a high content of nitrite and nitrate.

2. Ileostomy samples were decolourized with barium chloride, sodium sulphate and charcoal. Nitrite was determined spectrophotometrically by the Griess reaction and nitrate determined as nitrite after reduction with nitrate reductase $(E C 1.7 .99 .4)$ in the presence of sodium formate. The mean percentage recovery from twentysix spiked samples was 101.9 (SE 3.5) \% for nitrite and 82.9 (SE 3.3) \% for nitrate.

3. Ileostomy bag samples were obtained in twenty-nine cases of which ten had measurable nitrite (median 0 , range $0-20 \cdot 7 \mathrm{nmol} / \mathrm{g}$ ) on a conventional meal compared with twenty-three cases (median $7 \cdot 2$, range $0-31 \cdot 1 \mathrm{nmol} /$ g) on the test meal $(P<0.01)$. Nitrate levels were measurable in sixteen (median 6.7 , range $0-48.2 \mathrm{nmol} / \mathrm{g}$ ) after a conventional meal compared with twenty-one (median 20.5 , range $0-53.2 \mathrm{nmol} / \mathrm{g}$ ) after the test meal $(P<0.01)$.

4. Stomal fresh-catch samples were obtained in twenty-four cases: combined nitrate and nitrite was higher in eighteen, lower in four and unchanged in two subjects after the test meal $(P<0.05)$.

5. The type of foodstuff ingested can significantly alter measurable levels of nitrite-nitrate in the distal ileum and is one factor determining nitrite-nitrate input into the proximal colon.
\end{abstract}

The content of nitrite and nitrate in foods (White, 1975; Walker, 1975) has received considerable scientific attention (Ministry of Agriculture, Fisheries and Food, 1987) due to concern that these anions may generate $n$-nitroso compounds which have a carcinogenic potential in the gastrointestinal tract (Macdonald et al. 1984; Forman et al. 1985). Lately nitrite anions have been shown to interact metabolically with colonic mucosal cells (Roediger et al. 1986c) and enhance ion absorption and secretion in the colon (Roediger et al. 1986a; Radcliffe et al. 1987). These functions can be regarded as beneficial and suggest that the turnover of nitrite and nitrate is subject to metabolic mechanisms in the gastrointestinal tract which are as yet poorly understood.

Nitrite and nitrate enter the colon from the ileum (Tannenbaum et al. 1978; Saul et al. 1981; Bartholomew \& Hill, 1984), transmurally from the circulation (Thayer et al. 1982) or through synthesis of nitrite by inflammatory cells in the lamina propria (Stuehr \& Marletta, 1985; Iyengar et al. 1987). Ambient levels in the colon depend on a balance between absorption and secretion, as well as metabolism of nitrite by anaerobic bacteria (Hall, 1978) and colonic epithelial cells (Roediger \& Radcliffe, 1988). The precise quantities of nitrate and nitrite ions reaching the colon from the upper gastrointestinal tract are controversial. Tannenbaum \& Green (1981) reported ileal nitrite concentrations ranging from 350 to $1540 \mu \mathrm{mol} / \mathrm{kg}$, while Saul et al. (1981) reported lower ileal concentrations of nitrite $(0-15 \mu \mathrm{mol} / \mathrm{kg})$ and nitrate $(0-7 \mu \mathrm{mol} / \mathrm{kg})$. There is no standard method for determining nitrite and nitrate in ileal effluent, and wide variations in measured levels observed in the distal gastrointestinal tract have been attributed to the differing methods employed for measuring nitrite and nitrate (Ministry of Agriculture, Fisheries and Food, 1987). 
Table 1. Composition of test meal and estimated content of nitrate and nitrite derived from food tables (White, 1975; Walker, 1975)

\begin{tabular}{|c|c|c|c|}
\hline \multirow[b]{2}{*}{ Foodstuff } & \multirow{2}{*}{$\begin{array}{c}\text { Amount } \\
(\mathrm{g})\end{array}$} & \multicolumn{2}{|c|}{ Estimated amount (nmol) } \\
\hline & & $\mathrm{NO}_{3}^{-}$ & $\mathrm{NO}_{2}^{-}$ \\
\hline Frankfurter (two) & 120 & 0.49 & 0.26 \\
\hline Bacon (three slices) & 150 & 0.42 & 0.43 \\
\hline Spinach & 100 & $3 \cdot 06$ & 0.006 \\
\hline Beetroot & 50 & $2 \cdot 26$ & 0.006 \\
\hline \multicolumn{4}{|l|}{ Salad } \\
\hline Lettuce & 150 & 2.06 & 0.002 \\
\hline Radishes (five) & 50 & $1 \cdot 19$ & \\
\hline Celery & 50 & 1.89 & 0.017 \\
\hline Salad dressing as desired & - & - & - \\
\hline Squash drink & 100 & 0.66 & 0.002 \\
\hline
\end{tabular}

The present investigation was undertaken to establish a simple method of measuring nitrite and nitrate in ileostomy effluent, and to establish whether dietary change influenced the content of nitrite and nitrate in samples from ileostomies. Such an analysis had not been previously undertaken, and was also carried out to provide further information concerning nitrite and nitrate levels in the distal ileum in health.

\section{METHODS}

\section{Subjects and diets}

Thirty-one ileostomists were recruited from the Ileostomy Association of South Australia. All but one who had a terminal ileostomy for 6 months, had an ileostomy for at least 2 years. Ileostomies were performed for ulcerative colitis (twelve males and ten females) or Crohn's colitis (two males and seven females). All subjects were free of active disease, had normally functioning ileostomies and were off specific medication. Each subject gave informed consent before participating in the study.

Every subject consumed a self-chosen diet at home before the first visit to donate samples. Wherever possible the test meal was consumed the next evening, the composition of which is shown in Table 1 with approximate values for nitrite and nitrate calculated from analyses of Walker (1975) and White $(1975,1976)$. Actual nitrite and nitrate intakes were not analysed, but compliance assessed by completion of a questionnaire on the following morning.

\section{Sample collection and processing}

Attempts were made to collect two samples at each visit, termed 'bag' and 'stomal' sample. The bag sample was the contents of ileostomy bags present at 09.00 hours and the stomal sample was collected at the same time directly from the ileostomy orifice. Twenty-nine pairs (normal meal and test meal) of bag samples and twenty-four pairs of stomal samples were obtained for analysis.

The ileostomy effluent was collected into preweighed specimen bottles containing $10 \mathrm{ml}$ ice-cold $0.1 \mathrm{M}$-ammonium chloride buffer, $\mathrm{pH} 8.2$. The filled specimen bottle was weighed again and sufficient $\mathrm{NH}_{4} \mathrm{Cl}$ buffer added to give a $1: 1$ dilution of the effluent. The mixture was homogenized in a Waring blender (three $10 \mathrm{~s}$ bursts on high setting) and centrifuged at $12000 \mathrm{~g}$ for $30 \mathrm{~min}$ at $5^{\circ}$ to remove solid debris. The resulting supernatant fraction ranged in colour from pale straw-yellow to green-dark brown. To decolourize the sample $200 \mathrm{mg}$ activated charcoal, $2.0 \mathrm{ml} 1.0 \mathrm{M}$-barium chloride (recrystallized) and $2.0 \mathrm{ml} 1.05 \mathrm{M}$ - 
sodium sulphate were added to $4.0 \mathrm{ml}$ of the supernatant fraction in centrifuge tubes. The tubes were shaken for $1 \mathrm{~h}$ on an end-over-end shaker at room temperature and then centrifuged at $3200 \mathrm{rev} . / \mathrm{min}$ for $20 \mathrm{~min}$. The supernatant fraction was decanted into clean tubes and re-centrifuged, if necessary, to remove the last traces of charcoal. The resulting decolourized or, on occasion, slightly coloured supernatant was analysed for nitrite and nitrate. A colour blank was run for each sample, and the resulting absorbance used to correct for any residual colour.

It was necessary to recrystallize $\mathrm{BaCl}_{2}$ before use because Reagent Grade $\mathrm{BaCl}_{2}$ contained nitrate $(0.01 \mathrm{~g} / \mathrm{l})$ which gave unacceptably high background levels at the concentrations found in the ileal effluent. No interference was observed with recrystallized $\mathrm{BaCl}_{2}$ or from $\mathrm{Na}_{2} \mathrm{SO}_{4}$ or activated charcoal.

\section{Nitrite and nitrate assay}

Nitrite was determined spectrophotometrically using the Griess reaction. A portion of $500-1000 \mu \mathrm{l}$ was brought to $1000 \mu \mathrm{l}$ with distilled water, and $200 \mu \mathrm{l}$ sulphanilamide $(16 \mathrm{~g} / \mathrm{l})$ in $3.6 \mathrm{M}$-hydrochloric acid added followed by $50 \mu 1 \mathrm{~N}$-(1-naphthyl)-ethylenediamine $(1 \mathrm{~g} / \mathrm{l})$. A colour blank was run for each sample to which $50 \mu \mathrm{l}$ distilled water was added in place of the $N$-(1-naphthyl)-ethylenediamine. Absorbance was measured at $540 \mathrm{~nm}$, and the absorbance of each sample corrected by subtracting the absorbance of the appropriate blank.

Nitrate was determined as nitrite after reduction by a formate: nitrate reductase ( $E C$ 1.7.99.4) prepared from Escherichia coli $B$ as previously described (Radcliffe \& Nicholas, 1970; Radcliffe et al. 1987). Briefly, $500 \mu \mathrm{l}$ of the extract containing $10-40 \mathrm{nmol}$ nitrite plus nitrate was incubated with $500 \mu \mathrm{l}$ of an enzyme cocktail containing $0.2 \mathrm{nM}$-sodium formate, $12.5 \mathrm{mM}-\mathrm{Na}_{2}$ EDTA and $40 \mu 1$ nitrate reductase/ $\mathrm{ml}$ in $0.25 \mathrm{M}$-phosphate buffer (pH 6.0) for $16 \mathrm{~h}$ at $37^{\circ}$. Nitrite was determined as described previously. A colour blank was included for each sample, as well as an enzyme blank for each batch of samples. After correction for absorbance contributed by the colour blank, nitrate was calculated as total nitrite measured after incubation minus nitrite originally present in the sample and corrected for nitrate in the enzyme cocktail.

The final $\mathrm{pH}$ of the decolourized sample was critical for accurate determination of nitrate by the enzymic reduction to nitrite. The $\mathrm{pH}$ must be maintained above 7 to prevent the loss of nitrite that occurs under acid conditions and below 8 to avoid the inhibition or inactivation of nitrate reductase incurred above $\mathrm{pH} 8$ (Davis et al. 1985). $\mathrm{NH}_{4} \mathrm{Cl}$ buffer $(0 \cdot 1 \mathrm{M})$ adjusted to $\mathrm{pH} 8.2$ consistently produced a final extract with $\mathrm{pH}$ between $7 \cdot 0$ and $8 \cdot 0$. To minimize variability of nitrite estimation due to $\mathrm{pH}$, standard curves were prepared at the same $\mathrm{pH}$ as the $\mathrm{pH}$ of the sample that was analysed.

\section{Statistical analysis}

Values were subjected to analysis by the Mann-Whitney $U$ test or the paired $t$ test as appropriate.

\section{RESULTS}

In order to estimate the efficiency with which nitrite and nitrate were recovered from ileostomy effluent, a portion of each freshly collected sample was spiked with a known amount of nitrite or nitrate. The spiked samples were subjected to the standard decolourizing procedure. The mean recovery from twenty-six spiked samples was 101.9 (SE 3.5 ) $\%$ for nitrite and 82.9 (SE 3.3) \% for nitrate. The coefficients of variation for recoveries of nitrite and nitrate respectively were 3.4 and $4.0 \%$.

Nitrite and nitrate concentrations in ileal effluent were not significantly different with 

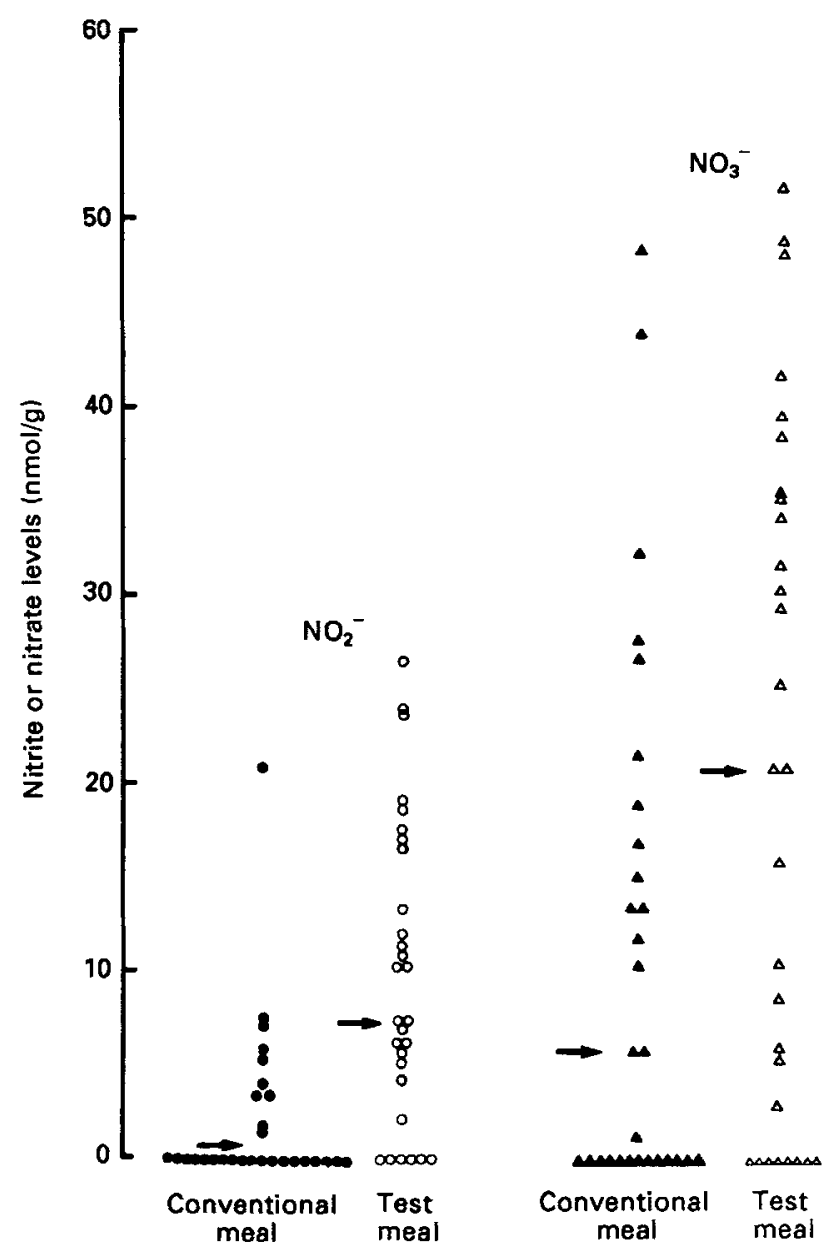

Fig. 1. Nitrite $(O, O)$ and nitrate $(\Delta, \Delta)$ levels of ilesotomy effluent (bag samples) after a conventional meal $(\boldsymbol{O}, \Delta)$ or test meal $(O, \Delta)$, expressed as $\mathrm{nmol} / \mathrm{g}$ wet weight. $\rightarrow$, Median value. For details of meals, see Table 1 and p. 324.

respect to ulcerative colitis or Crohn's colitis groups after either the conventional meal or test meal. The results were, therefore, analysed as a single group without reference to the reason for performing the ileostomy. Compliance with the experimental diet was good, each subject consuming at least $80 \%$ of the amount listed in Table 1.

In the bag samples detectable nitrite was found in ten of the twenty-nine samples after the conventional meal compared with twenty-three of the twenty-nine samples after the test meal (Figs. 1 and 2). The median concentration increased from 0 (range $0-20 \cdot 7$ ) nmol/g after the conventional meal to $7 \mathrm{nmol} / \mathrm{g}$ after the test meal. For nitrate, positive samples increased from sixteen of the twenty-nine samples after the conventional meal to twentyone following the test meal. The median nitrate concentration increased from 6.7 (range $0-48 \cdot 2$ ) to $20 \cdot 5$ (range $0-53 \cdot 2$ ) nmol/g for conventional and test meals respectively. Both these increases were statistically significant $(P<0.01$, Mann-Whitney $U$ test $)$.

For stomal samples, detectable nitrite increased from eight of the twenty-four samples after the conventional meal to sixteen after the test meal; the median nitrite concentration increased from 0 (range $0-29.9)$ to 5 (range $0-100 \cdot 8) \mathrm{nmol} / \mathrm{g}(P<0 \cdot 01$, Mann-Whitney U 


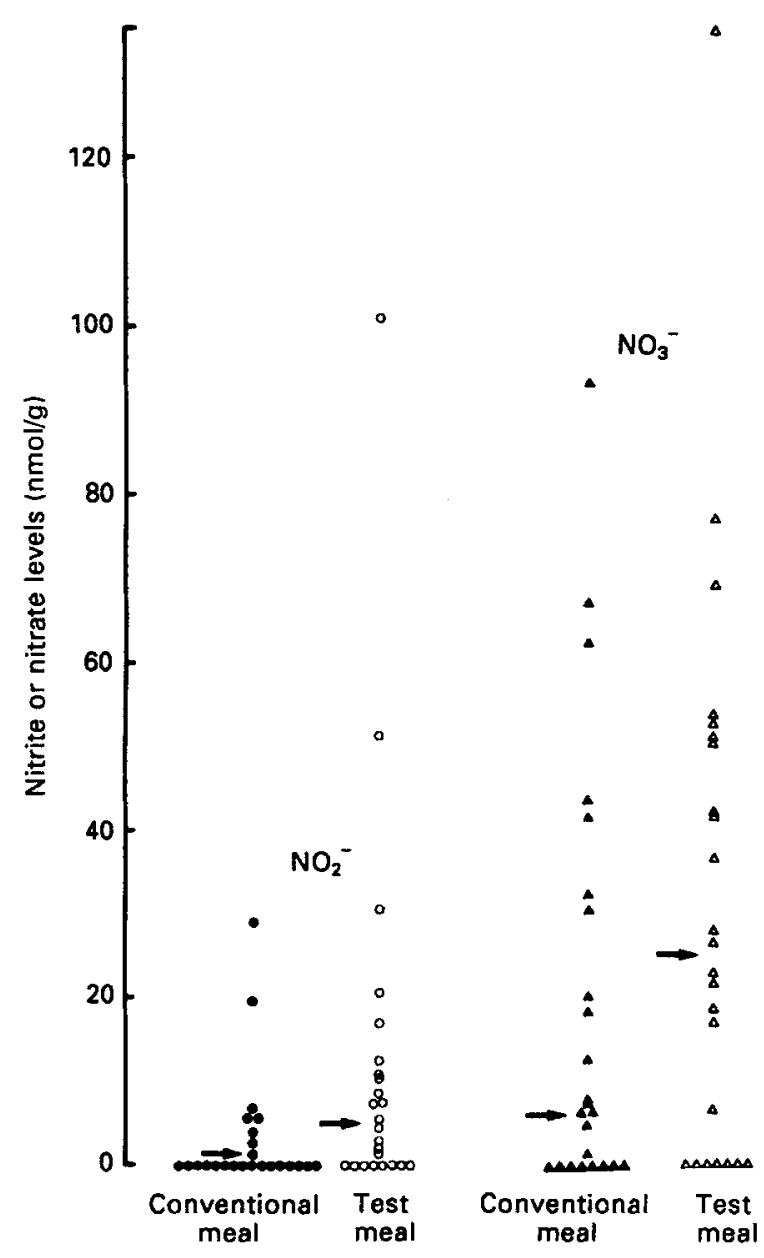

Fig. 2

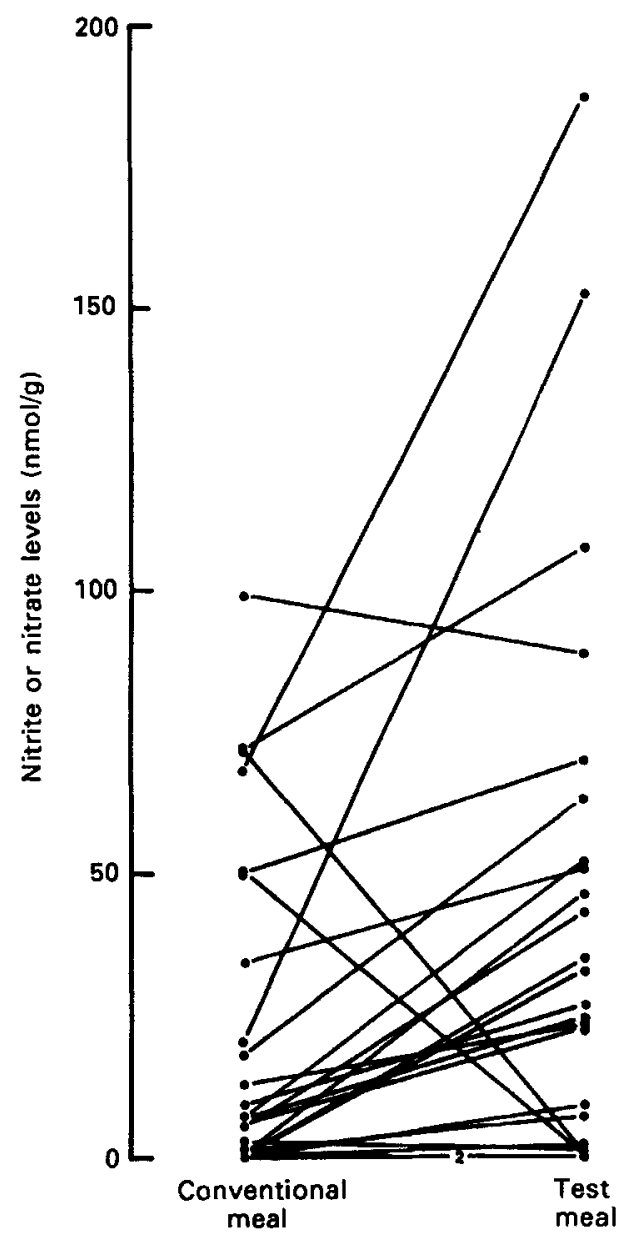

Fig. 3

Fig. 2. Nitrite $(O, O)$ and nitrate $(\Delta, \Delta)$ levels of ileostomy effluent (stomal sample) after a conventional meal or test meal, expressed as $\mathrm{nmol} / \mathrm{g}$ wet weight. $\rightarrow$, Median value. For details of meals, see Table 1 and p. 324.

Fig. 3. Comparison of total nitrate and nitrite (expressed as $\mathrm{nmol} / \mathrm{g}$ wet weight) in stomal samples for each subject after a conventional meal or test meal. For details of meals, see Table 1 and p. 324.

test). Although nitrate also tended to increase after the test meal in these samples (from 6.7 to $25 \cdot 1 \mathrm{nmol} / \mathrm{g}$ ), the difference did not reach statistical significance. However, comparing total nitrate plus nitrite in the stomal samples, after the conventional and test meals, eighteen of the twenty-four subjects had a higher total concentration after the test meal than after the conventional meal, four values decreased and two remained the same (Fig. $3)$. These changes were statistically significant $(P<0.05$; paired $t$ test).

\section{DISCUSSION}

The method of nitrite and nitrate analysis now reported differs from published methods of measuring nitrite and nitrate in biological samples in the manner in which samples were 
decolourized. Charcoal with barium chloride and sodium sulphate was used instead of the Carrez reagents (potassium ferrocyanide and zinc sulphate (Ruddell et al. 1976; Fox et al. 1982) or alumina gel (Stockbrugger et al. 1982)) because Carrez reagents may interfere with colour development in the Griess reaction if the ferrocyanide is not completely precipitated, and thus underestimation of the actual level of nitrite may occur (Fox et al. 1982). The following method was consequently used: dilution with an alkaline buffer, precipitation of particulate matter followed by adsorption of colour with activated charcoal and recrystallized barium chloride.

Enzymic reduction of nitrate has been used in measurements of nitrate in urine, saliva (Phizackerley \& Al-Dabbagh, 1983; Bartholomew 1984; Forman et al. 1985) and ileostomy effluent (Bartholomew \& Hill, 1984) where enzymic reduction was found superior to cadmium column reduction, a method employed previously in an analysis of nitrate in ileostomy effluent (Saul et al. 1981).

The observed recovery rates of nitrite and nitrate in spiked samples of twenty-six cases compare favourably with recoveries in spiked samples of two cases of ileostomy effluent of Saul et al. (1981) who reported recoveries of 82 and $76 \%$ for nitrite and nitrate respectively. In two further studies (Tannenbaum et al. 1978; Bartholomew \& Hill, 1984) in which nitrite and nitrate were estimated in ileostomy fluid, recovery rates for nitrite and nitrate were not reported.

Drawbacks of the current study were the lack of consideration of intestinal transit time in each subject and failure to measure the actual amounts of nitrate-nitrite ingested by each subject. Transit times to the distal ileum may vary from $80 \%$ recovery of a marker at 8.7 (SD 3.4) h (Holgate \& Read, 1983) to $100 \%$ recovery of a marker at 11.3 (SD 1.4) h (Chapman et al. 1985). Collection times of samples were kept constant and timed to $14-16 \mathrm{~h}$ after the meal eaten the previous night.

The experimental diet was chosen from foods likely to contain high nitrite and nitrate levels (Walker, 1975; White, 1975, 1976). Levels of nitrite and nitrate in vegetables vary with the degree of fertilization, plant age, part of plant used and exposure to sunshine (Breimer, 1982; Nelson, 1984; Greenwood \& Hunt, 1986), variables that were not controlled in the study. Despite these limitations it was possible to show that an acute change in diet significantly altered the concentration of nitrite in the distal ileum. Ishiwata et al. (1975) reported similar changes in response to dietary change when they measured nitrite content of saliva.

Values of nitrite reported for the first time from ileostomies by Tannenbaum et al. (1978) were very high, but subsequently stated to be incorrect in view of methodological difficulties experienced with the original analysis (Tannenbaum \& Green, 1981). Further studies (Saul et al. 1981; Bartholomew \& Hill, 1984) recorded much lower values than Tannenbaum et al. (1978). In order to facilitate comparison with the previously mentioned studies we expressed our results per unit wet weight, rather than dry weight, which is more accurate as it minimizes variability due to differences in absorption of water. Present concentrations of nitrite and nitrate were similar to those reported by Saul et al. (1981), who found nitrate in three and nitrite in seven of eight samples of ileal effluent collected from two subjects consuming a diet of free choice. They reported a concentration range of $0-15.0 \mathrm{nmol} / \mathrm{g}$ for nitrite and $0-7 \mathrm{nmol} / \mathrm{g}$ for nitrate. Present concentrations in bag samples after conventional meals ranged from $0-20.7 \mathrm{nmol} / \mathrm{g}$ for nitrite and $0-48.2 \mathrm{nmol} / \mathrm{g}$ for nitrate. Similarly to Bartholomew \& Hill (1984) we found that fresh-catch samples contained a higher concentration of nitrate than samples taken from the bag; differences, however, were not statistically significant. In view of the agreement with previous studies, and the larger number of subjects now studied, it seems likely that the values reported provide a good estimate of nitrate and nitrite reaching the distal ileum. 
In general the proportion of ingested nitrite and nitrate reaching the colon via the ileal lumen is very small (Ishiwata et al. 1981; Bartholomew \& Hill, 1984). While this proportion was not currently estimated, the amount of nitrite-nitrate actually entering the colon in total, especially transmurally from the circulation, is far greater than previously thought possible. Measurements indicate that approximately half the nitrate not removed in the urinary tract is transported from the bloodstream to the lumen of the large intestine and removed through metabolism of enteric bacteria (Thayer et al. 1982; Schultz et al. 1985). Dietary change may thus alter colonic nitrite and nitrate levels by routes other than the ileal lumen.

The demonstration that nitrite and nitrate reach the terminal ileum, and that the concentration of these anions is dependent on dietary intake, is of importance both to the physiological effect, e.g. absorption and secretion (Roediger et al. 1986a; Radcliffe et al. 1987), and pathological effect, e.g. nitrosamine formation (Suzuki \& Mitsuoka, 1981), that these ions may exert in the colon. Further work is required to determine the consequences of prolonged exposure of the lower gastrointestinal tract to nitrite and nitrate both in health and in such diseases as ulcerative colitis where high levels of lumen nitrite have been recorded (Roediger et al. 1986b).

The work was presented, in part, by B.C. R. at the Annual Meeting of the Canadian Society for Clinical Investigation and published as an abstract (Clinical Investigative Medicine (1985) 8, A94). The work was supported by a grant from the NH and MRC of Australia to W.E.W.R. The authors are gratefully indebted to the Chairman (Mr P. Dwyer), Committee and Members of the Ileostomy Association of South Australia for their cheerful co-operation in the study.

\section{REFERENCES}

Bartholomew B. (1984). A rapid method for the assay of nitrate in urine using the nitrate reductase enzyme of Escherichia coli. Food and Chemical Toxicology 22, 541-543.

Bartholomew, B. \& Hill, M. J. (1984). The pharmacology of dietary nitrate and the origin of urinary nitrate. Food and Chemical Toxicology 22, $789-795$.

Breimer, T. (1982). Environmental factors and cultural measures affecting the nitrate content in spinach. Fertilizer Research 3, 191-292.

Chapman, R. W., Sillery, J. K., Graham, M. M. \& Saunders, D. R. (1985). Absorption of starch by healthy ileostomate: effect of transit time and of carbohydrate load. American Journal of Clinical Nutrition 41, 1244-1248.

Davis, C. E., Leffler, R., Anderson, J. B., Soderberg, D. L. \& Meredith, F. I. (1985). Effect of pH on absorbance of azo dye formed by reaction between nitrite and sulfanilamide/ $N$-(1-naphthl)-ethylenediamine in residual nitrite methods for foods. Association of Official Analytical Chemists Journal 68, 485-488.

Forman, D., Al-Dabbagh, S. \& Doll, R. (1985). Nitrates, nitrites and gastric cancer in Great Britain. Nature 313, $620-625$.

Fox, J. B., Doerr, R. C. \& Lakritz, L. (1982). Interaction between sample preparation techniques and three methods of nitrite determination. Association of Official Analytical Chemists Journal 65, 690-695.

Greenwood, D. J. \& Hunt, J. (1986). Effect of nitrogen fertiliser on the nitrate contents of field vegetables grown in Britain. Journal of the Science of Food and Agriculture 38, 373-383.

Hall, J. B. (1978). Nitrate-reducing bacteria. In Microbiology 1978, pp. 296 298 [D. Schlessinger, editor]. Washington, DC: American Society of Microbiology.

Holgate, A. M. \& Read, N. W. (1983). Relationship between small bowel transit time and absorption of a solid meal. Influence of metoclopramide, magnesium sulfate, and lactulose. Digestive Diseases and Sciences 28 , 812-819.

Ishiwata, H., Boribdon, P., Nakamura, Y., Harada, M., Tanimura, A. \& Ishidate, M. (1975). Studies on in-vivo formation of nitroso compounds (II). Changes of nitrite and nitrate concentrations in human saliva after ingestion of vegetables or sodium nitrate. Journal of the Food Hygiene Society, Japan 16, 19-24.

Ishiwata, H., Mizushiro, H., Sakai, A. \& Tanimura, A. (1981). Distribution, secretion and metabolism of nitrate in the rat lower digestive tract. Journal of the Food Hygiene Society, Japan 22, 520-525.

Iyengar, R., Stuehr, D. J. \& Marletta, M. A. (1987). Macrophage synthesis of nitrite, nitrate an $N$-nitrosamines: precursors and role of the respiratory burst. Proceedings of the National Academy of Sciences, USA 84, 6369-6373. 
Macdonald, I. A., Mader, J. A., Rao, B. G. \& Malatjalian, D. A. (1984). Model systems demonstrating the volatile mutagenicity and carcinogenicity of sodium nitrite in rats. Experientia 40, 554-557.

Ministry of Agriculture, Fisheries and Food, (1987). Nitrate, nitrite and $N$-nitroso compounds in food. Food Surveillance Paper no. 20. London: H.M.S.O.

Nelson, D. W. (1984). Effect of nitrogen excess on quality of food and fiber. In Nitrogen in Crop Production, pp. 643-661 [R. D. Hauck, editor]. Madison, Wisconsin: American Society of Agronomy.

Phizackerley, P. J. R. \& Al-Dabbagh, S. A. (1983). The estimation of nitrate and nitrite in saliva and urine. Analytical Biochemistry 131, 242-245.

Radcliffe, B. C., Nance, S. H., Deakin, E. J. \& Roediger, W. E. W. (1987). Effect of luminal or circulating nitrite on colonic ion movement in the rat. American Journal of Physiology 253, G246-G252.

Radcliffe, B. C. \& Nicholas, D. J. D. (1970). Some properties of a nitrate reductase from Pseudomonas denitrificans. Biochimica et Biophysica Acta 205, 273-287.

Roediger, W. E. W., Deakin, E. J., Radcliffe, B. C. \& Nance, S. H. (1986a). Anion control of sodium absorption in the colon. Quarterly Journal of Experimental Physiology 71, 195-204.

Roediger, W. E. W., Lawson, M. J., Nance, S. H. \& Radcliffe, B. C. (1986b). Detectable colonic nitrite levels in inflammatory bowel disease - mucosal or bacterial malfunction. Digestion 35, 199-204.

Roediger, W. E. W. \& Radcliffe, B. C. (1988). Role of nitrite and nitrate as a redox couple in the rat colon. Implications for diarrheal conditions. Gastroenterology 94, 915-922.

Roediger, W. E. W., Radcliffe, B. C., Deakin, E. J. \& Nance, S. H. (1986c). Specific metabolic effect of sodium nitrite on fat metabolism by mucosal cells of the colon. Digestive Diseases and Sciences 31, 535-539.

Ruddell, W. S. J., Bone, E. S., Hill, M. J., Blendis, L. M. \& Walters, C. L. (1976). Gastric-juice nitrite. A risk factor for cancer in the hypochlorhydric stomach? Lancet ii, 1037-1039.

Saul, R. L., Kabir, S. H., Cohen, Z., Bruce, W. R. \& Archer, M. C. (1981). Re-evaluation of nitrate and nitrite levels in the human intestine. Cancer Research 41, 2280-2283.

Schultz, D. S., Deen, W. M., Karel, S. F., Wagner, D. A. \& Tannenbaum, S. R. (1985). Pharmacokinetics of nitrate in humans: role of gastrointestinal absorption and metabolism. Carcinogenesis 6, 847-852.

Stockbrugger, R. W., Cotton, P. B., Eugenides, N., Bartholomew, B. A., Hill, M. J. \& Walters, C. L. (1982). Intragastric nitrites, nitrosamines and bacterial overgrowth during cimetidine treatment. Gut 23, 1048-1054.

Stuehr, D. J. \& Marletta, M. A. (1985). Mammalian nitrate biosynthesis : mouse macrophages produce nitrite and nitrate in response to Escherichia coli lipopolysaccharide. Proceedings of the National Academy of Sciences, USA 82, 7738-7742.

Suzuki, K. \& Mitsuoka, T. (1981). Increase in faecal nitrosamines in Japanese individuals given a Western diet. Nature 294, 453-456.

Tannenbaum, S. R., Fett, D., Young, V. R., Land, P. D. \& Bruce, W. R. (1978). Nitrite and nitrate are formed by endogenous synthesis in the human intestine. Science 200, 1487-1489.

Tannenbaum, S. R. \& Green, L. (1981). Metabolism of nitrate. Banbury Report no. 7 Gastrointestinal Cancer: Endogenous Factors, pp. 331-341. Cold Spring Harbor: Cold Spring Harbor Laboratory.

Thayer, J. R., Chasko, J. H., Swartz, L. A. \& Parks, N. J. (1982). Gut reactions of radioactive nitrite after intratracheal administration in mice. Science 217, 151-153.

Walker, R. (1975). Naturally occurring nitrate/nitrite in foods. Journal of the Science of Food and Agriculture 26, 1735-1742.

White, J. W. Jr (1975). Relative significance of dietary sources of nitrate and nitrite. Journal of Agricultural and Food Chemistry 23, 886-891.

White, J. W. Jr (1976). Correction. Journal of Agricultural and Food Chemistry 24, 202. 